\title{
A organização do trabalho pedagógico da educação física escolar em um contexto de pobreza
}

\author{
The organization of school physical education pedagogical work in a context of poverty \\ La organización del trabajo pedagógico de la educación física escolar en un contexto de pobreza
}

\author{
Leonardo Lemos Silveira \\ Universidade Federal de Pelotas (UFPel), Brasil \\ leo.pf.ef@gmail.com
}

https://orcid.org/0000-0003-3982-4069

\author{
Giovanni Frizzo \\ Universidade Federal de Pelotas (UFPel), Brasil \\ gfrizzo2@gmail.com \\ https://orcid.org/0000-0003-0025-9947
}

\begin{abstract}
RESUMo:
$\mathrm{O}$ artigo trata de investigar a organização do trabalho pedagógico (TP) da Educação Física (EF) em contexto de desigualdade social e pobreza, a partir de uma investigação em uma escola da rede pública municipal de Pelotas. A pesquisa se caracteriza por ser do tipo exploratória (Gil, 2002) de caráter analítico interpretativo. Para tanto, a concepção de método de apropriação da realidade pelo pensamento se fundamentou no materialismo histórico dialético para que possamos realizar a análises dos dados da realidade. Para a escolha da escola que estivesse localizada em uma região de desigualdade social utilizamos os dados do Plano de Habitação de Interesse Social (PLHIS, 2013). Ao analisarmos as condições efetivas do trabalho pedagógico, começamos a compreender as relações existentes na organização do trabalho pedagógico da Educação Física e o contexto de pobreza. Assim, entendemos que tanto a escola como os professores e professoras realizam a reelaboração da organização escolar e do trabalho pedagógico para adaptarem a escola e suas aulas ao contexto social da localidade. Este estudo nos mostrou que existem movimentos resistentes, tanto dos professores e professoras como dos estudantes, ao modo de educação capitalista, partindo da reorganização do trabalho pedagógico para novas possibilidades que reelaboram o antigo para a aplicação do que é novo, do que foi transformado e superado.
\end{abstract}

PalaVras-chaVe: Educação Física, Pobreza, Desigualdade Social, Trabalho Pedagógico.

\section{Abstract:}

The article investigates the organization of the pedagogical work (PW) of Physical Education (PE) in the context of social inequality and poverty, based on an investigation in a public school in Pelotas. The research is characterized by being exploratory (GIL, 2002) and interpretative analytical in nature. Therefore, the conception of the method for appropriating reality through thought was based on dialectical historical materialism, so that we could carry out the analysis of reality data. To choose the school located in a region of social inequality, we used data from the Social Interest Housing Plan (PLHIS, 2013). By analyzing the effective conditions of pedagogical work, we began to understand the existing relationships between the organization of pedagogical work in Physical Education and the context of poverty. Thus, we understand that both the school and the teachers carry out the re-elaboration of the school organization and the pedagogical work to adapt the school and its classes to the local social context. This study showed us that there are resistant movements, both of teachers and students, to the capitalist mode of education, from the reorganization of the pedagogical work to new possibilities that re-elaborate the old for the application of what is new, of what has been transformed and overcome.

KEYwORDS: Physical Education, Poverty, Social Inequality, Pedagogical Work.

\section{RESUMEN:}

El artículo investiga la organización del trabajo pedagógico (TP) de la Educación Física (EF) en el contexto de desigualdad social y pobreza, a partir de una investigación en una escuela pública de Pelotas. La investigación se caracteriza por ser de tipo exploratorio 
(Gil, 2002) de carácter analítico interpretativo. Por tanto, la concepción del método de apropiación de la realidad a través del pensamiento se basó en el materialismo histórico dialéctico para que podamos analizar los datos de la realidad. Para elegir la escuela ubicada en una región de desigualdad social, utilizamos datos del Plan de Vivienda de Interés Social (PLHIS, 2013). Al analizar las condiciones efectivas del trabajo pedagógico, comenzamos a comprender las relaciones existentes en la organización del trabajo pedagógico en Educación Física y el contexto de pobreza. Así, entendemos que tanto la escuela como los docentes y docentes realizan la reelaboración de la organización escolar y el trabajo pedagógico para adecuar la escuela y sus clases al contexto social local. Este estudio nos mostró que existen movimientos de resistencia, tanto de docentes como de estudiantes, al modo de educación capitalista, partiendo de la reorganización del trabajo pedagógico hacia nuevas posibilidades que reelaboran lo antiguo para la aplicación de lo nuevo, lo que ha sido. transformado y superado.

Palabras clave: Educación Física, Pobreza, Desigualdad Social, Trabajo Pedagógico.

\section{INTRODUÇÃo}

O presente artigo trata de investigar a organização do trabalho pedagógico (TP) da Educação Física (EF) em contexto de desigualdade social e pobreza, a partir de uma investigação em uma escola da rede pública municipal de Pelotas localizada em um bairro pobre da cidade e que tem o pior IDEB do município.

Deste modo, compreendemos que toda a formação social que envolve a escola está sob uma complexa relação com o contexto social ao qual ela está inserida, independentemente de qual seja, entendemos que a organização do TP tende a se constituir através das desigualdades existentes em determinadas regiões. Portanto, como afirmam Freitas (1995), Silveira e Frizzo (2017) os contextos sociais influenciam de diversas formas no trabalho docente, inclusive podendo levar alunos e alunas pobres a abandonarem a escola pela necessidade de complementar a renda em suas casas ou até mesmo de já não encontrar na escola alguma perspectiva de vida futura

Igualmente, podemos observar que a desigualdade social pode se estabelecer devido a diversos fatores, e desta maneira para medi-la, de acordo com o Programa das Nações Unidas para o Desenvolvimento no Brasil (PNUD), são estimados em um cálculo, alguns elementos como: a renda que forma o padrão de vida digno; saúde e educação, por meio do Índice de Desenvolvimento Humano Ajustado à Desigualdade (IDHAD).

Segundo o PNUD de 2016, o Brasil se encontra na posição 79 entre os 188 países, estagnado no Índice de

Desenvolvimento Humano $\left(\right.$ IDH $^{1}{ }^{1}$ ), com o valor de 0,754 em 2014. Se tratando do IDHAD, "um método que relativiza o desenvolvimento humano em função da diferença entre os mais e menos abastados de um país" (PNUD, 2017, p. 1), o Brasil é um dos países que mais vem perdendo posições.

Outro indicador que nos auxilia na compreensão da desigualdade social no Brasil é o "Coeficiente de Gini (2010-2015) - instrumento mede o grau de concentração de renda em determinado grupo e aponta a diferença entre os rendimentos dos mais pobres e dos mais ricos" (PNUD, 2017, p.1). Neste indicador, o Brasil, tendo em vista países da América Latina e Caribe, ocupa o quarto lugar, ou seja, é o quarto pior país da América Latina e Caribe para os mais pobres. Deste modo o Brasil fica atrás somente de países como Haiti que ocupa o primeiro lugar, Colômbia em segundo e Paraguai em terceiro.

Levando em consideração que o Brasil é o pior lugar da América Latina e do Caribe para os mais pobres, segundo dados do PENUD (2017), é necessário para pessoas que vivem em situação de pobreza no país trabalhar mais, e muitas vezes, em condiçóes que não são adequadas para o trabalho, encarando jornadas de trabalho precarizado com baixos salários e sem nenhuma segurança. Podemos perceber isso, a partir de uma lista fornecida pelo Ministério do Trabalho em 2016, que relata 350 nomes de empresas autuadas por caracterização do trabalho análogo ao escravo. A lista se remete aos casos de 2005 até 2016 cujas as decisões finais, condenações, nos processos foram estabelecidos entre abril de 2014 e abril de 2016 (BRASIL, 2016).

Podemos entender que as condições precárias de vida da população acabam por colocar os trabalhadores e trabalhadoras em condições igualmente precarizadas de trabalho, já que a população que vive em condições de extrema pobreza e pobreza não observa outra saída senão aceitar estas relações de exploração do trabalho 
para garantir sua sobrevivência. Neste cenário, a grandes empresas veem na população que estão em situação de extrema pobreza e pobreza a oportunidade de estabelecer o tipo de "contratação" e lucrar, pois estão preocupadas com os custos de produção de suas mercadorias e com o acúmulo de capital.

Portanto, tendo em vista tais problemas estruturais do sistema, partimos para compreender como a pobreza afeta o trabalho dos professores e professoras da disciplina de EF da rede pública de ensino. Assim sendo, nosso problema de pesquisa tenta compreender como se organiza o TP da EF em um contexto de desigualdade social.

Igualmente, a pesquisa ${ }^{2}$ objetivou analisar a organização do TP da EF em uma escola pública da rede municipal de Pelotas no Rio Grande do Sul (RS) que estivesse imersa em um contexto de desigualdade social. Como forma de atingir nosso objetivo, partimos para a análise de alguns elementos que pudessem nos encaminhar para a resposta de nosso problema de pesquisa, assim, entendemos que se tornou necessário compreender como é organizado o TP da EF; averiguar como são estabelecidos os conteúdos da EF e de que forma são desenvolvidos em relação aos estudantes e problematizar a relação entre o TP dos professores e professoras da EF e estudantes, perante a desigualdade social da localidade.

\section{Metodologia}

A presente pesquisa ${ }^{3}$ se caracteriza por ser do tipo exploratória (Gil, 2002) de caráter analítico interpretativo. Igualmente, o foco desta pesquisa é a desigualdade social e seus desdobramentos na organização do TP da EF. Para tanto, a concepção de método de apropriação da realidade pelo pensamento se fundamentou no materialismo histórico dialético, pois compreendemos que este modo de observar o mundo parte de uma forma de entender a realidade, ou seja, de concepção de mundo e da vida, também, enquanto práxis, essa compreensão de mundo busca a transformação a partir da compreensão da realidade (Frigotto, 2000). Com o fim de selecionarmos uma escola municipal da zona urbana de Pelotas no Rio Grande do Sul (RS) que atendesse nossos interesses de pesquisa, partimos a seleção do bairro com maior índice de desigualdade. Deste modo, fizemos uso do quadro de distribuição de renda retirado do Plano de Habitação de Interesse Social (PLHIS, 2013), no qual são expostos gráficos de distribuição de renda por bairro de Pelotas. Ao analisarmos gráfico podemos perceber que o bairro com menor distribuição de renda é o bairro Barragem, porém, segundo o site da Secretaria Municipal de Educação e Desporto (SMED) de Pelotas no Rio Grande do Sul (RS), a escola que está localizada nesta região é de educação infantil, assim não entrando em nossa seleção, pois não possui da disciplina de EF nesta etapa de ensino. Portanto, partimos para o segundo bairro com menos distribuição de renda, sendo esse o bairro Três Vendas.

Para que pudéssemos decidir qual escola realizaríamos a pesquisa, decidimos por selecionar aquela que tivesse a menor pontuação no Índice de Desenvolvimento da Educação Básica ${ }^{4}$ (IDEB) de 2015, deste modo, selecionamos a escola que nomearemos como escola da rede municipal de Pelotas (ERMP). Para a realização do trabalho de coleta de dados, após realizar as devidas solicitações para realizarmos a pesquisa, convidamos os professores e professoras a participarem da pesquisa. Assim, foram selecionados todos os docentes que lecionavam nos $6^{\circ}$ a $9^{\circ}$ anos do ensino fundamental e, também, aqueles que atuassem no Ensino de Jovens e Adultos (EJA), nas séries finais. Para a coleta de dados dos docentes foram realizadas observações das aulas de todos os 6 docentes da disciplina de EF com o intuito de compreender como se dá a organização do TP da EF em um contexto de pobreza. Também, foram realizadas junto aos docentes uma entrevista com um roteiro de 7 perguntas abertas elaboradas exclusivamente para atender os interesses desta pesquisa. Aplicamos um questionário com 9 questóes abertas (Gerhardt \& Silveira, 2009), para os estudantes $\operatorname{dos} 8^{\circ}$ e $9^{\circ}$ anos do ensino fundamental e igualmente, foi aplicado o questionário aos estudantes do EJA ( $7^{\mathrm{a}}$ e $8^{\mathrm{a}}$ série). A aplicação do questionário a estes anos/séries de ensino se dá por cona destes alunos e alunas estarem nas últimas etapas desse nível de ensino e terem uma vivencia maior com a disciplina de EF e entender de que forma os estudantes 
desta escola percebem a EF em relação ao seu contexto social. Dos 240 alunos das turmas de $8^{\circ}, 9^{\circ}$ anos, $7^{\mathrm{a}} \mathrm{e}$ $8^{a}$ série onde 145 eram alunos frequentes, foram devolvidos 62 questionários que foram analisados.

\section{DesiguALDADE SOCIAL E O TP DA EF}

Nossa pesquisa parte do entendimento de que o contexto social que envolve a escola se relaciona diretamente com a organização do TP da EF, deste modo, partimos para a compreensão de como se organiza o TP da disciplina de EF em um contexto de pobreza. Ao analisarmos os dados da realidade percebemos certas questões que se relacionavam com o trabalho docente (TD), durante as aulas de EF.

Para iniciarmos as análises é necessário compreender que partimos de uma visão de mundo que entende que o modo de produção da vida atual necessita de um projeto educacional que atenda aos interesses de mercado, o que se contrapõe à uma perspectiva de formação humana, e para os interesses mercadológicos importam mais os resultados finais da produção da força de trabalho do que os valores educacionais para a mudança da realidade de jovens e crianças no sistema escolar. Desta maneira, podemos perceber o ideal colocado pelas correntes liberais que buscam desassociar os estudantes de sua realidade concreta, como se essas não influenciassem em suas condições dentro da escola, e sendo assim, para que os estudantes pudessem seguir estudando até o término da Educação Básica bastaria apenas se "esforçarem mais".

Assim, se constitui um dos processos de fragmentação do ensino, que compreende a separação da atuação dos alunos e alunas e dos docentes, negando que na atuação dos estudantes está contida e diretamente ligada à sua realidade social - e essa é indissociável - assim como é a dos professores e professoras no processo educativo. Durante as observações e entrevistas com os docentes, podemos observar que as realidades dos estudantes interferiam diretamente na organização do TP da EF, assim como também na aprendizagem dos alunos e alunas. Já que a escola estava localizada em um bairro pobre e que a maioria dos estudantes tinham dificuldades com roupas, alimentação, etc. as aulas de EF eram desenvolvidas, pensando nestes estudantes.

Ao questionarmos aos docentes se o contexto social interfere na aprendizagem dos alunos e alunas, os docentes, em sua maioria, relatam que interfere totalmente, como podemos observar na fala deste professor.

A sim, direto, uma pessoa mal alimentada ela não rende tudo aquilo que poderia render, as vezes tu vê as pessoas muito desanimadas cedo pela manhã, tens que entender esse momento e tu não pode querer que faça coisas que ele não está em condições físicas para fazer (P1, grifos nossos).

As condições efetivas de vida dos alunos e alunas não ficam fora dos muros da escola, pelo contrário, elas entram e se configuram como parte da organização do TP da EF. A partir deste relato, podemos questionar: quais as oportunidades efetivas, segundo a lógica liberal, de um estudante que não possui condições, por exemplo, de poder se alimentar e se vestir tem de superar suas dificuldades e "vencer na vida"? Segundo a lógica liberal, bastaria se esforçar. Em contrapartida, podemos questionar quais são essas condições frente a um outro estudante que possui as possibilidades de vestir-se e alimentar-se. Notem que estamos falando em apenas duas dimensões das condições de satisfazer as necessidades básicas. Observamos, que uma das docentes relata essa diferença em uma de suas falas.

[...] ]a criança que é bem-criada, bem cuidada ela desenvolve mais. Eu tenho alunos no sexto ano que não sabem o que é direita e esquerda. Tu entendes isso? Que é uma coisa básica e isso é uma coisa que teria que ser trabalhada bem antes só que, daqui a pouco até foi trabalhado só que eles estavam tão cansados com tanta fome que [...] eles não conseguiram aprender nada. Vem mais no caso, na realidade acho que o ideal deles é vou ir pra lá para me alimentar, para ter um porto seguro pra ficar, porque isso aqui é assim, aqui é um porto seguro, as vezes na tua casa não é assim, no caso deles, muitas vezes não é (P3, grifos nossos).

A docente explica essa relação em sua fala, os alunos e alunas possuem dificuldades que são referentes às condições de sua realidade. A escola acaba sendo, em primeiro plano, um local para satisfazer suas necessidades básicas, neste caso, comer e se sentir seguro, acolhido. A parte educativa poderia ser algo a mais, que, mesmo 
assim, é dificultada por suas condições. Estaria o estudante centrado no processo de ensino/aprendizagem sem ter suas necessidades básicas completamente supridas?

Igualmente, existem outros fatores sociais que dificultam o acesso à educação, um destes elementos é apresentado na fala de uma das professoras (P4) entrevistadas, como as possibilidades de acesso à cidade como um todo, as questóes culturais da cidade de Pelotas, entre outros. O que parece ser dificultado em decorrência do afastamento do bairro, onde a ERMP se localiza, da zona central da cidade de Pelotas ${ }^{5}$ (Figura 1).

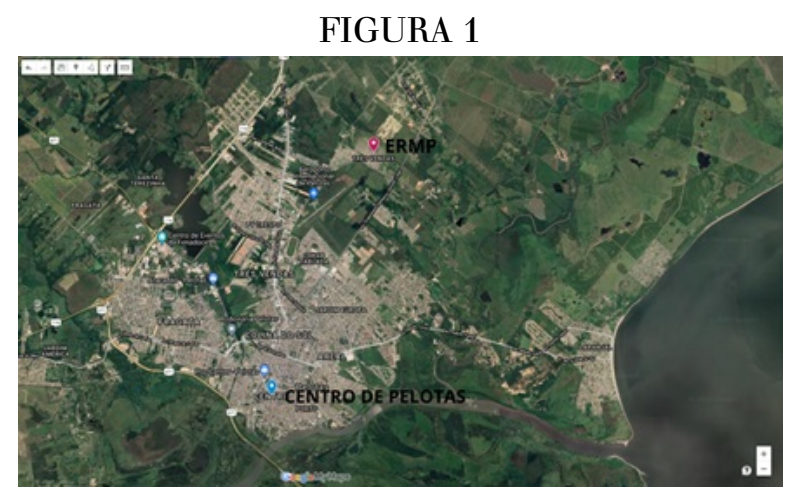

Fonte: Imagem editada a partir de Google My Maps

Também, os alunos e alunas, segundo a docente, apresentam uma visão limitada do que eles almejam para suas vidas. Isso, pode ser reflexo das condições estruturais e históricas de serviços públicos e políticas públicas que possam dar acesso às pessoas que vivem no bairro a melhores condições de vida, já que necessitam trabalhar para sobreviver, limitando-se àquilo que a realidade os apresenta, como sendo algo para a sua sobrevivência.

Do restante das questões sociais, acho que é muito impactante até no acesso, a gente tem alunos, por exemplo, que não conhecem nada além do bairro deles, tu pergunta "qual a cidade que tu moras?" eles falam "Getúlio Vargas" por exemplo, então essa visão de mundo, essa noção de que Pelotas é muito além do bairro [...] essa noção de acesso né, uma coisa..., é um bairro muito deslocado do centro, então dificulta também essa questão deles acessarem, por exemplo prédios históricos ou o que que é a prefeitura, então quando conversamos com os alunos de coisas assim... de visão de mundo, "qual é o teu sonho?", “o que tu quer ser?” Eles falam, por exemplo, não é desmerecer a profissão, “eu quero ser caixa de supermercado [...]”, é uma visão, às vezes, muito limitada até, dessa noção do que é o tamanho do que eles podem ser [...] (p.4).

Para compreender melhor as dificuldades enfrentadas pelos estudantes, utilizamos as respostas do questionário entregue aos alunos e alunas. No que tange as perguntas relacionadas as suas dificuldades na realização das aulas de EF, como roupa adequada, alimentação, habilidades, entre outras. Notamos uma contra tendência (Frizzo, 2012) em suas respostas, já que os estudantes, em sua maioria (62\%), responderam que não tinham nenhum tipo de dificuldade. Olhamos para aqueles que fugiram a essa regra e direcionavam suas respostas para as questões efetivas de vida para a prática da EF. Existe um dado que nos chama a atenção, um dos estudantes respondeu que não possui nenhuma dificuldade para a realização das aulas de $\mathrm{EF}$, porém, ele responde da seguinte forma "não, porque a escola fornece alimento e roupas, habilidade nós temos" (Aluno $7-8^{a}$ A Manhã). Entendemos que o aluno emprega na escola, um ambiente que, neste momento, ameniza suas dificuldades com um ou mais determinados problemas, neste caso, roupas e alimentação. $\mathrm{O}$ estudante responde, em um primeiro momento, que não possui dificuldades, mas delega isso à escola que o auxilia. Outro aluno, diz que possui dificuldades: "sim, roupa adequada, tipo para fazer exercícios físicos os esportes e também falta de algumas habilidades no esporte” (Aluno $1-9^{\circ} \mathrm{B}$ Manhã).

Podemos então, compreender como a escola se torna importante para os estudantes e, consequentemente, para a comunidade, na tentativa de auxiliar os alunos e alunas com seu problemas rotineiros, mesmo que não 
sejam resolvidos em sua totalidade, já que são problemas estruturais deste sistema, que de certa forma, são amenizados, dando um pouco de condições para os estudantes.

Durante as observações, percebemos que os alunos e alunas tiravam os seus tênis para a realização das práticas nas aulas de $\mathrm{EF}$, e isso se dava, segundo o docente, devido às poucas possibilidades dos estudantes de terem um calçado, sendo esse o único que possuíam, não poderiam estragá-lo, caso contrário, não teriam condições de comprar outro.

Os estudantes costumam jogar descalços para que não estraguem seus tênis. [...] O professor explica que é normal essa situação acontecer, como eles não querem estragar o calçado acabam por jogar sem, e por muitas vezes se machucam (Diário de campo, 1 de agosto de 2018).

Essa condição especifica é relatada por um dos alunos (mesmo tendo sido um fator recorrente nas observações). Este diz que sua dificuldade é relacionada "Só com roupa, porque as vezes eu não jogo futebol porque eu venho com meus tênis novos" (Aluno $1-8^{\circ} \mathrm{B}$ Manhã). Outro elemento, é a fala do docente que explica as possibilidades de poder cobrar a vestimenta dos estudantes.

[...] se uma criança não tem o que comer, como é que eu vou cobrar dele que tenha a roupa adequada, o tênis adequado para fazer a EF, se ele não tem o caderno e o lápis, como é que ele vai ter a roupa, pra mim é mais importante a participação dele do que..., mesmo que seja de pés descalços que é o que muitos fazem (p.5).

Os relatos apresentados até aqui apontam que alunos, alunas e docentes não são agentes neutros no processo de ensino e aprendizagem, não estão, ao atravessar os protões da escola, envolvidos em um ambiente asséptico, controlado, que permita a igualdade de condições para os estudos, onde livra-se de todas as interferências e o que resta é apenas a força de vontade e perseverança. Essa "realidade" não existe, pelo menos, não para aqueles que estão diariamente no campo da ação pedagógica e que precisam lidar com os problemas sociais que envolvem seus estudantes.

Por conta disso que nenhum indivíduo pode estar inserido no mundo com outras pessoas assumindo ser neutro, não podemos olhar e apenas observar e constatar de maneira asséptica o que está ao nosso redor sem questionar, sem intervir (Freire, 2014). Uma das professoras entrevistadas questiona sobre as possibilidades de aprendizagem dos alunos e alunas quando chegou à escola e percebeu as dificuldades dos mesmos.

[... eu entrei na escola e primeiro eu dei aula para os pequenos, $3^{\circ} \mathrm{e} 4^{\circ}$ ano, e aí tinham alguns que não sabiam escrever o nome, e eu fiquei chocada eu questionava: será que o problema é dos alunos? Será que o problema é na escola? Será que o problema é na família? É no ambiente que ele vive, que ele está, que não é incentivado? Ou será que o problema vem desde a gestação que a mãe não se alimentou bem, não desenvolveu tudo que precisava? Entende, mas é direto assim, eu me questionei muito quando entrei na escola, e eu via que os alunos não conseguiam simplesmente não sabem, eles não aprendem, eles tem dificuldade, tanto no aprendizado para escrever, tanto pra ler, tanto para correr, quanto para pular as crianças elas não sabem brincar $[\ldots]$ (p. 2, grifos meus)

$\mathrm{Na}$ fala desta professora, podemos perceber seus questionamentos frente ao impacto que a realidade dos alunos e alunas da escola causa no seu ser docente, tentando procurar formas de entender/explicar as deficiências educacionais e motoras dos seus estudantes. O direcionamento das questões estão centradas nos indivíduos, porém, podem ser trabalhadas e aprofundadas de modo a compreender que os elementos contidos na desigualdade social auxiliam no aprofundamento das desigualdades educacionais.

Os problemas relacionados ao incentivo ao estudo; à estrutura familiar, base de auxílio aos estudos; às condições de nutrição, não são os motivos que levam às desigualdades educacionais em si, mas são os efeitos das desigualdades sociais e os meios pelos quais os alunos e alunas apresentam tais desigualdades educacionais. São produtos da pobreza, pelos quais ela se manifesta, assim como é, também, a desigualdade educacional. Assim é importante compreender que:

Os alunos e alunas, geralmente, não possuem o devido incentivo em casa devido as suas condições de vida. Ou os pais não sabem ajudar ou não têm condições devido a sua carga de trabalho. 
[...] eles vão para a casa a mãe não sabe ler para ajudar, eles vão para a casa a mãe não quer ajudar, então eles não têm uma estrutura familiar que possa vir a complementar esse trabalho da sala de aula [...] (p. 5).

Outro ponto importante, diz respeito a importância dos estudos para os estudantes da ERMP: alguns estudantes (37\%) expressam o fato de que a educação seja para conseguir um emprego melhor, outros $27 \%$ apontam-na como forma de obter um futuro melhor para suas vidas, como seguem as respostas:

Sim, é importante porque assim ficamos inteligentes, nos formarmos e arrumamos trabalhos bons (Aluno 7 - $8^{\circ} \mathrm{A} \mathrm{Manhã,}$ grifos nossos).

Sim, porque estudar faz você crescer em conhecimento para arrumar um bom emprego, para ter um bom salário e ser uma pessoa inteligente (Aluno $4-8^{\circ} \mathrm{B}$ Manhã, grifos nossos).

Sim, para no futuro ter um bom emprego e bastante dinheiro (Aluno $3-9^{\circ} \mathrm{B}$ Manhã, grifos nossos).

Acho importante estudar porque a escola me dá um futuro melhor do que eu posso ter lá fora (Aluno 13 - $9^{\circ}$ A Manhã, grifos nossos).

As respostas em suma estão diretamente ligadas às possibilidades de os alunos e alunas conseguirem uma forma de sustento, um futuro melhor. Isso pode estar diretamente ligado às condições estruturais de subsistência dos estudantes da escola. Anseiam por uma educação que os proporcione melhores condições de vida. Observamos que essa conceituação de que a escola, por meio de seus ensinamentos, auxiliará na elevação social está diretamente ligada às falas dos alunos e alunas. Remetemos isso à posição da escola nesta sociedade, produtora de mão de obra e que possa satisfazer aos interesses do mercado. No entanto, vale ressaltar que ela - a escola - forma para a empregabilidade e não para o trabalho propriamente dito, tornando-se uma forma de preparação para os postos de trabalho em disputa, porém, sem garantia nenhuma de efetivamente conseguir um emprego (Frizzo, 2012).

Outro ponto, é referente ao seu desejo em relação ao que pretendia ser no futuro. As respostas apontavam para questões diversas, mas algumas chamaram nossa atenção, pois, elencavam pontos de ajuda ao próximo e segurança. Deste modo, 20\% dos estudantes colocam com desejo de profissão a área militar/segurança, das quais foram apresentadas Policial, General e Bombeiro; e direcionadas para ajuda ao próximo, paz, etc., assim como descrito nessa resposta: "Eu pretendo ser (PM) Policial Militar, este é meu foco, porque acho legal, quero acabar com tudo que é de errado, ter paz" (Aluno $9-9^{\circ}$ B Manhã).

Também percebemos o foco por profissões que de alguma forma auxiliem as pessoas, como é o caso da advocacia (8\%), na área médica (6,4\%): "Ser advogada! Por que eu sempre sonhei em ser advogada, para lutar pelo direito de cada pessoa" (Aluna $8-9^{\circ} \mathrm{A}$ Manhã); "Médica, porque quero cuidar e curar muitas pessoas" (Aluna 16 - $9^{\circ}$ A Manhã). Outras profissões apresentadas são: Veterinário(a) (11\%); Engenharia Civil (5\%). Também, surgiram mais profissões que alocamos no item, outras profissões que totalizaram 16\%, outros estudantes que ainda não sabem exatamente o que querem somaram $16 \%$.

Igualmente é importante observarmos os dados da realidade, o Brasil encontra-se em um momento em que a quantidade de pessoas desempregadas ${ }^{6}$ (13,4 milhões) torna as possibilidades de acesso ao trabalho muito escassas. Assim, tornando cada vez mais distante da realidade a ideia de que a educação é um fator importante para que os estudantes consigam um emprego, já que as possibilidades de conseguirem vencer a disputa por um emprego diminuem em um país onde a taxa de desocupação da população de 18 até 24 anos é de 27,3 $\%$ (IBGE, 2019a; 2019b).

Percebemos durante as observações das aulas de EF e das folhas de chamadas que alguns dos estudantes estavam com muitas faltas. O docente explica que devido às condições financeiras das famílias, muitos alunos e alunas acabam tendo que trabalhar e essa questão acaba afetando a frequência escolar e, consequentemente, seu aprendizado. Podemos observar isso nas anotações a seguir: 
O professor explica que de forma geral, não são todos os alunos e alunas que se matriculam na escola que efetivamente cursam. Ele explica que alguns estudantes não aprecem ou faltam muito e só reaparecem quando o concelho tutelar vai até suas casas. Neste caso, para que os estudantes não "rodem" na disciplina por infrequência o professor os avalia durante os dias em que frequentou as aulas, alguns dos demais professores que realizam provas e trabalhos discutem sobre a reprovação dos estudantes de ano durante os concelhos de classe. Para eles, dependo do aluno e da nota que precisa para passar de ano é interessante deixar que este passe, e dar uma chance para ele ir para o próximo ano, isso gera discussões nos concelhos de classe, já que alguns professores não concordam (Diário de Campo, 31 de julho de 2018).

A frequência dos estudantes, em alguns casos tem relação com as possibilidades dos alunos e alunas em auxiliar na renda familiar, como relata o docente:

[...] alguns as vezes para ficar cuidando de irmãos, saiu pai, saiu mãe e tem que ficar com irmão menor, ai quem fica, fica o irmão mais velho e deixa de vir para a escola ou porque tem que ajudar em casa, tem que fazer alguma coisa tem que ganhar o pão de cada dia e ai deixa de vir a escola para fazer algum bico, as vezes quando eles não vem aqui, tu encontra no centro cuidando carro, fazendo alguma coisa assim para ganhar algum dinheiro, ou porque não gosta de estudar mesmo, não vê futuro porque não tem referência, entendesse, na família, as vezes na família ninguém estudou, ganham dinheiro de outra forma $[\ldots]$ (p. 1, grifos nossos).

Devido às condições em que os alunos e alunas desenvolvem seu aprendizado, a escola acaba por tomar medidas para que os estudantes não acabem por desistir dos estudos. Deste modo, a forma como se apresenta a organização escolar pode sofrer alterações, devido a essas condições. Em nossas observações, notamos essa preocupação nos relatos dos docentes durante a reunião pedagógica, ao falar sobre um aluno em especifico.

Observamos, no fragmento de entrevista do docente P1, que as condições estruturais condicionam as relações que os alunos e alunas têm com o processo educativo, em decorrência de seu contexto social e as possibilidades de acesso ao conhecimento historicamente produzido. São elementos de sua construção social. Isso mostra que as condições efetivas de vida da população estão diretamente relacionas às condições educacionais.

Os estudantes acabam por serem explorados pelo capital, devido sua necessidade. A condição de pobreza auxilia na evasão escolar condicionando os alunos e alunas a se inserirem, mesmo que de forma ilegal, no mercado de trabalho. Por sua vez, ao tentar diminuir a evasão escolar, o sistema foca em controlar esse problema através de leis que obrigam os estudantes menores de idade, a voltar para a escola. Os alunos e alunas que voltam para a escola acabam sofrendo com maiores déficits educacionais até que se tornem adultos perante a lei e não seja mais de obrigatoriedade do Estado de mantê-los dentro do sistema educacional. É garantido o acesso à escola para todos, no entanto, não é garantida a qualidade deste ensino, muito menos a permanência dos estudantes na instituição de ensino.

Portanto, trata-se de uma "inclusão excludente", não sendo garantida uma educação que proporcione a "[...] formação de identidades autônomas intelectuais e eticamente, capazes de responder e superar as demandas do capitalismo [...]" (Kuenzer, 2005, p. 92), partindo, assim, para uma educação que atenda as demandas do capital, através de resoluções rápidas e eficientes, sem a pretensão de que os trabalhadores e trabalhadoras possam estabelecer um pensamento crítico sobre o que estão realizando e que possam apenas realizar uma determinada função.

Deste modo, observamos uma escola sob a perspectiva hegemônica, que auxilia na reprodução das desigualdades e do próprio sistema do capital. No entanto, é importante compreender que ao mesmo tempo também pode ser uma ferramenta de resistência contra a hegemonia do sistema dominante, para essa possibilidade de emancipação, enquanto superação da formação do trabalhador e da trabalhadora para o mercado, só é possível enquanto houver resistência dentro do próprio sistema de ensino expresso na luta de classes. E mesmo que a lógica hegemônica do capital impere na organização do currículo escolar, docentes e estudantes são fundamentais para a reorganização, mesmo que mínima, de uma escola que possa dar conta de uma formação crítica para além do capital. Assim, é necessário entender que não basta apenas pensar uma mudança na escola capitalista, mas é necessário romper com essa lógica do sistema para que possamos buscar uma alternativa educacional distinta (Mészáros, 2008). 
$\mathrm{Na} \mathrm{EF}$ tem se estabelecido diversas vertentes que em determinados momentos históricos servem à continuidade do status social vigente, o que pode ser ligado as influencias das instituições militares e médicas e que podem estar ligadas às necessidades do capital, expressas em concepções pedagógicas distintas em períodos históricas diferentes do Brasil e que são contrapostas por movimentos contra hegemônicos, assim como é na educação de forma geral. Já que as influências do sistema hegemônico na educação são organizadas por meio das próprias necessidades do capital, não seria diferente para a EF que irá atender a essas exigências, por meio de políticas públicas educacionais. O que auxilia como contraponto são os movimentos de resistem as investidas do capital na educação.

A EF escolar, está condicionada às relações sociais inerentes ao contexto de sua atuação, deste modo, os aspectos relacionados às desigualdades sociais estão em constante aglutinamento com as atividades relacionadas, também, a esta disciplina. Isso interfere na forma como os estudantes se apropriam dos conteúdos da disciplina de EF. Um dos docentes entrevistados explica de seguinte forma:

\begin{abstract}
$\mathrm{Na}$ outra escola que eu trabalho ela é uma escola central, mas o público, é na EJA também, [...] então o público é de uma periferia de um outro bairro da cidade, mas é um público de periferia que encontra, mais ou menos as mesmas dificuldades que encontro aqui, mas não no nível tão grande quanto aqui, entende? [...] então assim, não é que a ideia de construção dos objetivos das aulas são os mesmos, mas o clima da aula é diferente, porque tem menos essas questóes da violência verbal entre eles, mesmo que seja entre eles, o número de alunos é um pouquinho maior, eles conseguem..., eu consigo propor atividades diferentes que as vezes aqui [na ERMP] pela limitação não tem, a estrutura da escola é melhor a quadra é adequada é uma quadra grande coberta, bem iluminada, que não tem goteira, que eu tenho o material[...] (p. 6, grifos nossos).
\end{abstract}

Observe que as condições de vida possuem certas semelhanças, como relata o docente. Porém, note que as atividades relacionadas aos conteúdos da EF são novamente, segundo o docente, melhor trabalhados na outra escola por questões estruturais e materiais e, inclusive, também pelas condições de existência dos estudantes. Em outro fragmento da entrevista o docente diz o seguinte: “[...] lá eu consigo trabalhar de uma maneira mais completa, consigo ter uma evolução maior nas propostas de desafios, na dificuldade que eu tenho aqui é assim mais relativizada por essa dificuldade" (P6). Podemos dizer que o processo de ensino é diferente, referente a diversos fatores mencionados anteriormente. $\mathrm{O}$ docente está se referindo às condições do estudante em relação ao aprofundamento de sua proposta de ensino, deste modo, entendemos que a apropriação dos alunos e alunas, nestas duas realidades, são distintas e condicionadas pelos seus contextos sociais.

Igualmente, tivemos respostas similares de outro professor, que leciona em uma escola Estadual. Ele explica que as condições estruturais e materiais da escola do Estado são melhores, o que proporciona ao docente trabalhar com atividades que não conseguiria na ERMP.

Totalmente diferente, até porque o público é diferente já é um público de uma classe social um pouco melhor (na escola do Estado) [...]tu vê pela condição de vestuário..., de tudo né que é diferente, lá a própria escola dá uma condição diferente de trabalho [...] então eu consigo fazer as atividades com eles que eu não consigo fazer aqui [na escola] por falta de local de espaço de várias coisas (P1, grifos nossos).

As condições de apropriação dos conteúdos podem estar diretamente ligadas às possibilidades de aplicação dos mesmos, pois os docentes relatam que as dificuldades estruturais dessa aplicação, na escola pesquisada, limitam as possibilidades de atividades da EF. Também, questionamos ao professor P1 se o conteúdo é o mesmo em ambas as escolas: "A mesma coisa que eu faço aqui eu faço lá (escola do Estado), entende lá eu vejo um entendimento melhor da minha proposta de trabalho [...]” (p. 1).

É importante salientar que não é pelo fato de que existe um determinado modo de progressão e aprofundamento nas atividades do docente em outras escolas da mesma rede de ensino que estes alunos e alunas têm acesso ao conhecimento historicamente elaborado, de forma que essa apropriação emancipe-os, ou compreenda a carga teórica do conteúdo da cultura corporal em sua totalidade e complexidade. Porém, pode nos mostrar que exista um plano de demanda do capital por tipos específicos de trabalhadores e trabalhadoras para assumir postos de trabalho no modo de produção capitalista, já que "o conhecimento científico e 
o saber prático são distribuídos desigualmente, contribuindo ainda mais para aumentar a alienação dos trabalhadores" (Kuenzer, 2005, p. 79).

As respostas apresentam elementos importantes para a compreensão da complexa relação existente entre a comunidade e a escola, e apresenta pontos para entender as necessidades estruturais e educacionais das camadas empobrecidas da população. Também mostra que a escola como um todo auxilia naquilo que pode para que os alunos e alunas consigam estar da melhor forma possível, participando das aulas. Observamos em um dos relatos dos docentes que acabam trazendo roupas e calçados para que os alunos e alunas possam ter o que vestir, mostrando que, por mais que as condições de trabalho sejam precarizadas, tanto pela via das condições estruturais, materiais e salariais, quanto pelas condições de vida da população do bairro, os docentes se importam com os alunos e alunas do bairro e se esforçam para que os mesmos possam ter condições de aprender.

Eu trago uma roupa de casa para eles, tênis, sapato, calça, tem gurias que não tem mesmo, eu sei porque não é um filho, são cinco, seis filhos, então a gente traz bastante coisas para eles, eu trago particularmente, tem um monte de professor que eu conheço trazem $[\ldots]$ (p. 3)

Questionamos aos estudantes sobre os pontos positivos e negativos da escola, as respostas dos alunos e alunas mostram como sendo um dos fator positivo da escola é a merenda, podemos constatar isso com uma das falas dos docentes sobre a importância da merenda para os estudantes “[...] às vezes, as pessoas já chegam perguntando pela merenda, e tu vê que a merenda para eles é importante, talvez seja o único alimento, um alimento importante para o dia deles, a gente vê bastante isso assim” (p. 1): assim, 12\% dos estudantes dizem gostar da merenda e também do horário em que ela é distribuída aos alunos e alunas da escola. Isto mostra que a escola tenta atender as demandas advindas desse contexto. Os estudantes colocam sento elementos positivos da escola pontos como: o comprometimento dos docentes (33\%), 9,6\% dos estudantes apontam como aspecto positivo a aprendizagem, remetendo não somente aos professores e professoras, mas também o que pode ser um fator escolar como um todo.

Outro ponto é o relacionamento dentro da escola, que agrega questões como amizade e respeito, por exemplo, que somam 11\%, mostrando que a escola tenta organizar um ambiente próprio para o ensino e aprendizagem. Igualmente, os funcionários recebem apontamentos positivos dos estudantes: $11 \%$ dos alunos e alunas explicam ter um bom relacionamento com os funcionários da escola. "Os aspectos positivos são: professores dispostos a ajudar, os funcionários ótimos" (Aluno 7 - $9^{\circ} \mathrm{A}$ Manhã). "Acho bons os professores, responsáveis, são professores dispostos a ajudar" (Aluno 12 - $9^{\circ}$ A Manhã). "Positivos - gosto bastante da escola, é uma escola boa para estudar" (Aluno $8-9^{\circ}$ A Manhã). Outra respostas dos alunos e alunas sobre os aspectos positivos e negativos da escola nos chama a atenção, o estudante diz o seguinte: "Para mim só de ter uma escola, a oitava, dentro do bairro já é bom, ruim é não ter o ensino médio" (Aluno 2 - Vespertino $7^{\circ} \mathrm{A}($ Série)).

A escola torna-se importante para os moradores do bairro, que querem dar seguimento aos estudos, mas não tiveram a possibilidade em algum momento de sua vida. Isso nos faz refletir sobre as condições efetivas de estudo que os moradores deste bairro possuem, e nos elementos que constituem esse processo. Uma das professoras explica que "a escola está inserida em uma realidade bem difícil, que é difícil de tu compreender se tu não está aqui, também não só a questão de alimentação, mas questão do convívio social” (p. 2). A professora também explica as condições de vestimenta dos estudantes e diz que no

Inverno é bem complicado assim, e com as crianças, tem várias que vem o inverno e elas com pouquíssima roupa, de tu ter que ir na coordenação e pedir uma roupa, porque normalmente tem, porque o pessoal doa para botar naquela criança, porque tá com chinelo com 5 graus (p. 5).

As respostas são importantes para a compreensão da complexa relação existente entre a comunidade e a escola, e apresenta pontos para entender as necessidades estruturais e educacionais das camadas empobrecidas 
da população. Também mostra que a escola como um todo auxilia naquilo que pode para que os alunos e alunas consigam estar da melhor forma possível, participando das aulas.

Os alunos e alunas em suas respostas, sobre pontos positivos e negativos, também apresentaram elementos negativos sobre a escola. Os estudantes (38\%), expõem problemas estruturais ${ }^{7} \mathrm{da}$ escola, em sua maioria problemas referentes às salas de aulas, quadras, falta de ventilação, entre outros, seguem os relatos:

Para começar, não tem sala de aula o suficiente para comportar todos os alunos, como por exemplo, minha turma, estudo em um laboratório e a outra turma estuda em um auditório, na minha turma não tem classes o Para começar, não tem sala de aula o suficiente para comportar todos os alunos, como por exemplo, minha turma, estudo em um laboratório e a outra turma estuda em um auditório, na minha turma não tem classes o suficiente para os alunos (Aluno 13 - $9^{\circ} \mathrm{B}$ Manhã).

[...]os aspectos negativos: salas de aulas destruídas, biblioteca sempre fechada, escola destruída, etc. laboratório em situações precárias, banheiros em situação muito ruim [...] salas de aula fedendo a esgoto, materiais de química velhos, salas de aula insuficiente, livros didáticos em mau uso [...] salas de aulas não terminadas, falta de armários, e os armários que tem estão destruídos e velhos, muro pichado, lixo no chão, grades nas janelas parecendo um presídio, mato grande atrás e nos lados da escola, quadra de esportes não pintada, campinho de futebol destruído, muro destruído, bebedouro ruim e quebrado, auditório em mau estado, sala de informática pequena e sem professores, refeitório em mau estado, com mesas quebradas [...] pátio de escola destruído, quadros quebrados, valetas sujas perto da escola [...] (Aluno $14-9^{\circ} \mathrm{B}$ Manhã).

Esses elementos podem nos fazer compreender melhor as condições estruturais da escola, e assim compreendemos, conforme Nidelcoff (1989, p. 14), que explica que as condições das escolas onde os estudantes de família abastadas estudam são "[...] superiores às condições das escolas de bairro ou de regiões pobres do país. Isso impossibilita a alguns, e não permite a outros, uma série de experiências [...].

O que é descrito pelos estudantes são problemas que aumentam a precarização do TD. A constante crise do sistema capitalista demanda formas de agenciamento para que este sistema tenha uma sobrevida. "O capitalismo é uma forma de organização social que vive de crises. A crise é o momento em que o capitalismo, por consenso ou pela força, posterga seus problemas, renova suas forças e ganha tempo" (Freitas, 1995, p. 115). Os ajustes são de "superfície em vários planos - o econômico, o político, o social, o cultural" (Nozaki, 2015, p. 61). Igualmente, trazendo diversos agravos ao trabalho abstrato, "tendo como manifestações o desemprego estrutural e a precarização do trabalho" (Nozaki, 2015, p. 61). Os professores e professoras além de reorganizarem suas práticas e produzirem novos conhecimentos a partir do contexto social, também tratam de lidar com os problemas estruturais da degradação do sistema público de ensino.

Durante as observações, pudemos notar que cada professor e professora possui uma maneira diferente de desenvolver suas aulas, alguns mais centrados em aulas mais "livres", outros trabalhando conteúdos específicos, através de estafetas e também aclimatando o desenvolvimento das aulas de acordo com as condições dos estudantes. Durante as entrevistas, questionamos os docentes sobre a organização das aulas, quais os objetivos e os conteúdos que desenvolvem durante o ano letivo.

Bom, eu trabalho desde que eu vim para cá com os esportes coletivos, voleibol, handebol, basquete e futebol, teve ano que junto com isso trabalhei capoeira, atletismo e também a gente trabalha bastante a parte recreativa, [...] até esse ano foi muito mais aula livre, como eles chamam, do que uma aula mais orientada para esses esportes coletivos. E o objetivo que eu tenho como esporte e as atividades que eu faço é mostrar para eles a importância do esporte e a formação através do esporte, uma questão mais comportamental eu dou muito valor para isso, das pessoas cooperarem, compartilharem momentos (p. 1, grifos nossos).

Nas respostas dos alunos e alunas, ao questionarmos o que eles aprendiam nas aulas de EF, observamos uma porcentagem elevada dos estudantes (53\%) que responderam que aprendem sobre os esportes (futebol, basquete, vôlei e demais alunos e alunas que responderam apenas que aprendem esportes). Também responderam que aprendem lutas (25\%), jogos (22\%), exercícios (14\%), regras (11\%). Podemos perceber que a EF apresenta elementos esportivos, que são padronizados para essa disciplina, e que estes não incluem a gama de conteúdos da cultura corporal (jogos, ginástica, dança, esportes, lutas, entre outros). Desta forma, 
não compreendendo a expressão corporal, desenvolvida histórica e socialmente, se não como um todo, em parte.

Tendo em vista que a carga de conhecimento dos conteúdos da EF, que são trabalhados na formação dos professores e professores da área, abrangem conhecimentos que não se restringem aos esportes, temos uma certa tendência a esse conteúdo nas escolas, porém, parece que apenas" [...] algumas modalidades esportivas tais como o futebol, basquetebol e voleibol fazem parte do conteúdo das aulas de Educação Física. Outras modalidades como o atletismo e a ginástica artística raramente são difundidas entre os escolares" (Betti, 1999, p. 25). Também, a esportivização constitui-se a partir de elementos como "a saúde, a capacidade de trabalho/rendimento individual e social [...] (Bracht, 1999, p. 74). Mesmo apresentando em sua proposta pedagógica conteúdos mais distintos, a aula da EF ainda ocorre "balizada pelo paradigma da aptidão física e esportiva" (Bracht, 1999, p. 78). A predominância do esporte nas aulas de EF, é citado por outros autores (Mariano, Miranda \& Metzner, 2017; Neu \& Terrazzan, 2017).

Deste modo, o esporte tornou-se um conteúdo hegemônico nas aulas de EF, assim, outras vivências corporais não são abarcadas quando o esporte é o conteúdo majoritariamente trabalhado nas aulas (Betti, 1999). O intuito aqui não é tratar de retirar o esporte enquanto conteúdo das aulas da disciplina, mas de apontar este como sendo um conteúdo dentre vários que compõem a EF e que deve ser apresentado para os alunos e alunas, porém, sem a exclusão dos demais.

Com relação as formas de avaliação do aprendizado nas aulas de EF, no contexto pesquisado, os professores e professoras apresentam as seguintes formas de avaliação: avaliações teóricas e avaliações práticas. Nas avaliações teóricas, realizam a avaliação por meio de provas e trabalhos. Estes, em alguns casos, são trabalhos de aplicação, os quais os estudantes irão desenvolver nas aulas práticas, apresentando para seus colegas. Neste sentido, Freitas (1995, p. 95) explica que a avaliação "é um momento real, concreto e, com seus resultados, permite que o aluno se confronte com o momento final idealizado, antes, pelos objetivos".

Nas avaliações práticas, os professores e professoras realizam avaliações dos alunos e alunas a partir do seu desenvolvimento durante as aulas práticas da Educação Física, e podem agregar nessas avaliações, aspectos individuais e ou de grupo. Para aqueles que desenvolvem sua avaliação na forma teórica e prática, tivemos as seguintes respostas:

P2M: Sim, eu apliquei prova. O segundo trimestre eu não consegui aplicar porque eu entrei na metade, então eu não conhecia muito bem os alunos e já tive que avaliar eles, a partir do pouco que tinha visto, não em uma progressão que realmente foi dada. Mas nesse terceiro trimestre eu fiz metade da nota, prática e metade da nota de uma avaliação teórica, uma prova que eu fiz com eles.

Pesquisador: E na prática, tu avalias o entendimento deles do conteúdo a evolução que eles têm nesse período? P2M: Exato! Principalmente a evolução e a dedicação pra ti aprender algo, porque tem crianças, tem jovens que eles tem um aparato motor bom e eles já entram e já sabem, entre aspas, é muito mais fácil o aprendizado e tem o aluno que não tem, então eu não posso um com o outro [comparar] tipo, a tá jogando e não tá jogando, mas sim com ele mesmo, quanto aquele aluno conseguiu evoluir entende, ou se não evoluiu, quanto ele se dedicou para aquilo. Tem alunos que eles não tiveram uma melhora tão significativa assim, mas foram alunos que se dedicaram e que tem todo um contexto por trás, e antes disso que não deixaram talvez evoluir tanto (p. 2, grifos nossos).

A docente manifesta em sua fala seu processo de avaliação, realiza-o de duas formas: de forma teórica, por meio de provas e trabalho, e de forma prática, através da participação, evolução, entre outros. Também, demonstra preocupação com a forma de evolução dos alunos e alunas para estabelecer sua avaliação prática, ou seja, como os alunos e alunas progrediram durante um determinado período de tempo, sempre levando em conta as condições de cada estudante. Igualmente, na avaliação, os professores e professoras parecem se preocupar em quais condições os alunos e alunas realizam a aula de EF e qual contexto tem por de trás dos estudantes que avaliam.

Entre os professores e professoras que desenvolvem suas avaliações mais direcionados às atividades práticas da EF, que podem agregar aspectos avaliativos, individuais ou de grupo, um dos docentes explica o seguinte: 
[...] minha avaliação ela já foi diferente eu já fiz prova, trabalho com eles, já avaliei individualmente, hoje minha avaliação ela é uma avaliação coletiva, eu entendo hoje que o coletivo supera a questão individual [...] (p. 1).

Vele ressaltar que, a escola capitalista "encarna objetivos (funções sociais) que adquire do contorno da sociedade na qual está inserida e encarrega os procedimentos de avaliação, em sentido amplo, de garantir o controle da consecução de tais funções” (Freitas, 1995, p. 95). Ou seja, se estabelece forma de garantir, da melhor forma possível, as necessidades do sistema.

Percebemos, durante as entrevistas, que existem elementos que modificam o ser docente no ato de avaliar. No decorrer de sua atuação, os professores e professoras acabam por reorganizar suas formas de percepção de avaliação dos alunos e alunas para não cometer injustiças, como explica o docente:

[...] lá no início de minha carreira, que a gente avaliava individualmente, fez nota $\mathrm{X}$ não, fez nota $\mathrm{Y}$, mas eu via que dessa forma eu cometia injustiças tanto para mais como para menos nas notas, aluno que as vezes observando de forma individual era excelente, mas que para o grupo ele tinha uma influência ruim, porque não deixava os demais realizarem ou por uma brincadeira ou pelos demais acharem que não conseguiram chegar no nível dele. Então tudo isso a gente tenta conversar e fazer eles entenderem..., leva um tempo, as vezes tu passa um ano e tu não consegue que eles captem a ideia da questão do coletivo ser mais importante que a questão do individual (p. 1).

Esses elementos mostram como os professores e professoras reorganizam seu TP na disciplina de EF neste contexto e como a organização social capitalista interfere, de diversas formas, no decorrer do TD. Também, como os estudantes se estabelecem no processo de ensino-aprendizagem, a partir de um contexto de pobreza e de precarização do ensino públicos.

\section{Considerações Finais}

Dentro dos elementos descritos até aqui, podemos estabelecer categorias que surgem das análises e que nos ajudam com nosso problema de pesquisa, que se trata de compreender como se organiza o TP da EF em um contexto de desigualdade social? Partirmos para a primeira categoria, a esportivização da EF, em que as aulas da disciplina apresentam um direcionamento para os conteúdos relacionados aos esportes (futebol, futsal, basquete, vôlei, handebol, atletismo, etc.). A esportivização da EF ainda se encontra integrada à prática pedagógica da EF.

A esportivização da EF, apresentada como desenvolvimento dos conteúdos relativos ao esporte, é predominante nas aulas da disciplina. Deste modo, partimos para a compreensão desta para que possamos pensar em possibilidades de superação para a formação humana dos alunos e alunas, com o intuito de pensar possibilidades de desenvolvimento deste conteúdo, de forma que proporcione aos estudantes a vivência de todos os conteúdos da cultura corporal.

Outra categoria apresentada a partir das análises é a avaliação nas aulas de EF. Observada nas respostas dos professores e professoras, mostram como se estabelece a carga avaliativa do aprendizado. Assim, na EF, percebemos formas de trabalhos avaliativos distintos realizados pelos professores e professoras da escola pesquisada: apresentam os conteúdos da disciplina em avaliações teóricas: provas e trabalhos, e também utilizam avaliações nas aulas práticas, com relação ao comportamento, envolvimento e desenvolvimento do aluno e da aluna no decorrer das aulas na quadra.

Outro ponto mostra que os docentes tendem a organizar suas avaliações em vista das condições dos alunos e alunas, em relação as suas condições de vida. No entanto, mesmo que o docente se mostre sensível aos processos avaliativos do aprendizado dos alunos e alunas em decorrência de sua realidade, esses processos são realizados a partir da lógica pré-estabelecia da escola capitalista, que demanda a necessidade de continuidade do aluno e da aluna dentro da escola pública. A avaliação na escola capitalista torna-se ferramenta de verificação para observar quem atende melhor aos objetivos e ao sentido que a escola tem para a formação dos alunos e alunas. 
A categoria que mais parece estar presente nas relações que os professores e professoras têm com a forma que organizam seu TP, com o fim de melhor atender os alunos e alunas, é a categoria o sentido da EF em um contexto de pobreza. Observamos que a disciplina tende a ser remetida como elemento de descontração/ recreação e felicidade para os alunos e alunas, pois em decorrência de seu contexto social acabam por ter, na disciplina, um momento em que esquecem de seus problemas. Outro ponto é que para alguns professores e professoras a disciplina acaba abarcando o sentido de acolhimento da EF, porque acabam por organizar todo seu TP a partir das condições de existência dos estudantes e, em determinados momentos, apresentam questóes relativas ao amparo dos alunos e alunas como, por exemplo, a doação de roupas e no pensar de suas aulas sobre questóes especificas dos alunos e alunas, como trabalhar questóes de coletividade, ajuda ao próximo, entre outros.

Todos os elementos que compõem as categorias impactam na formação dos alunos e alunas que vivem em um contexto de pobreza. Os processos de ensino passam pelas condições de existência destes estudantes; a esportivização, ainda muito presente nas aulas de EF, mesmo que com uma ênfase diferente de outras épocas, aponta elementos para a formação dos alunos e alunas que não abrangem outros conteúdos da disciplina e colocam na EF o caráter de formadora para o esporte.

A forma como se elabora a avaliação tende a levar em consideração as possibilidades de aprendizagem dos estudantes que se encontram nestas condições de pobreza. Partem de avaliações que visam os processos de desenvolvimento dos alunos e alunas nas aulas e que irão atingi-los de formas distintas no decorrer do seu processo educativo, já que os professores e professoras possuem formas diferentes de avaliar o conhecimento dos estudantes e levam em conta seu contexto social. Isso faz com que os alunos e alunas tenham acesso ao conhecimento de formas diferenciadas, ora mais centrado nas questóes do coletivo, da ajuda, da vivência dos conteúdos da EF, ora mais centrado na compreensão sistematizada dos conteúdos desenvolvidos pelos professores e professoras.

Por fim, assim como a escola vai perdendo seu sentido de formadora para o trabalho, a EF vai perdendo o sentido de disciplina curricular para os alunos e alunas e tomando um novo sentido: o do acolhimento, o do lazer, o de momentos de descontração, o da alegria, o da coletividade. Por isso, a organização do TP tende a agrupar esses elementos e desenvolvê-los em suas aulas para atender a essas necessidades dos alunos e alunas.

Ao analisarmos as condições efetivas do trabalho pedagógico, começamos a compreender as relações existentes na organização do trabalho pedagógico da Educação Física e o contexto de pobreza. Entendemos que tanto a escola como os professores e professoras realizam a reelaboração da organização escolar e do trabalho pedagógico para adaptarem a escola e suas aulas ao contexto social da localidade. Este estudo nos mostrou que existem movimentos resistentes, tanto dos professores e professoras como dos estudantes, ao modo de educação capitalista, partindo da reorganização do trabalho pedagógico para novas possibilidades que reelaboram o antigo para a aplicação do que é novo, do que foi transformado e superado.

Portanto, tratamos de responder nosso problema de pesquisa, que tenta compreender como se organiza o TP da EF em um contexto de desigualdade social? Deste modo, o TP da EF se organiza a partir da compreensão dos elementos oriundos do contexto onde está sendo desenvolvido este trabalho, neste caso, um contexto de pobreza. Para isso, tende a constituir formas de abarcar os alunos e alunas e compreender sua realidade. Para atender a demanda dos estudantes, o TP se organiza em elementos que organizamos em categorias que também fazem parte do processo de organização da escola capitalista. Ao longo da investigação, foi possível identificar que os elementos principais que constituem a organização do TP da EF são: a esportivização, a avaliação meritocrática e o sentido da EF em um contexto de pobreza. Este último, com uma subcategoria que trata do sentido de acolhimento da EF, na perspectiva de amenizar os efeitos subjetivos das precárias condições materiais de existência dos estudantes. 


\section{REFERÊNCIAS}

Betti, I. C. R. (1999). Esporte na escola: mas é só isso, professor? Motriz, I (1), 25-31, junho. Disponível em: < http:/ /www.rc.unesp.br/ib/efisica/motriz/01n1/4_Irene_form.pdf >. Acesso em: 25 de maio de 2019.

Bracht, V. (1999). A constituição das teorias pedagógicas da educação física. Cadernos Cedes, XIX, (48), Agosto. Disponível em: < http://www.scielo.br/pdf/\%0D/ccedes/v19n48/v1948a05.pdf >. Acesso em: 25 de maio de 2019.

Brasil. (2016). Ministério do Trabalho e Previdência Social. Serviço de Informação ao Cidadão - SIC do Ministério do Trabalho e Previdência Social ao Repórter Brasil. jun. Disponível em < 91 https://www.sinait.org.br/docs/listade transparencia4.pdf >. Acesso: 17 de maio de 2017.

Freire, P. (2014).Pedagogia da autonomia: saberes necessários à prática educativa / Paulo Freire - 49a ed - Rio de Janeiro: Paz e Terra. 143 p.

Freitas, L. C. de. (1995). Crítica da organização do trabalho pedagógico e da didática/ Luiz Carlos de Freitas. Campinas, SP: Papirus. — (Coleção Magistério: Formação e Trabalho Pedagógico). 288 p.

Frigotto, G. (2000). O Enfoque da dialética materialista histórica na pesquisa educacional. In: FAZENDA, I. (Org.). Metodologia da pesquisa educacional.6.92 Ed. São Paulo: Cortez. p. 69-90 (Blibioteca da Educação, Série I, Escola v. 11).

Frizzo, G. F. E. (2012). A organização do trabalho pedagógico da Educação Física na escola capitalista. Tese (Doutorado) - Universidade Federal do Rio Grande do Sul, Escola Superior de Educação Física, Programa de Pós-Graduação em Ciências do Movimento Humano, Porto Alegre. Disponível em < http://hdl.handle.net/10183/60392 > Acesso em: 30 de outubro de 2017.

Gerhardt, T. E. \& Silveira, D. T. (2009). Métodos de pesquisa / [organizado por] Tatiana Engel Gerhardt e Denise Tolfo Silveira; coordenado pela Universidade Aberta do Brasil - UAB/UFRGS e pelo Curso de Graduação Tecnológica Planejamento e Gestão para o Desenvolvimento Rural da SEAD/UFRGS. - Porto Alegre: Editora da UFRGS. 120 p.

Gil, A. C. (2002). Como elaborar projetos de pesquisa. 4 a. ed., São Paulo, Atlas. 176 p.

IBGE. (2019a). Agência IBGE Notícias. Desemprego sobe para 12,7\% com 13,4 milhöes de pessoas em busca de trabalho. 30 de abril. Disponível em: < https://agenciadenoticias.ibge.gov.br/agencia-noticias/2012-agenciadenoticias/not icias/24283-desemprego-sobe-para-12-7-com-13-4 milhoes-de-pessoas-em-busca-de-trabalho >. Acesso em: $27 \mathrm{de}$ maio de 2019.

IBGE. (2019b). Pesquisa Nacional por Amostra de Domicílios Continua: PNAD Contínua. Mercado de Trabalho. $1^{\circ}$ trimestre de 2019b. Disponível em: < https://static.poder360.com.br/2019/05/Pnad-continua-ibge-desemprego.p $d f>$. Acesso em: 27 de maio de 2019.

Kuenzer, A. Z. (2005). In: LOMBARDI, J. C., Saviani, D. \& Sanfelice, J. L. (orgs.). Capitalismo, trabalho e educação. - 3. Ed. - Campinas, SP: Autores Associados, HISTEDBR. 176p. - (Coleção educação contemporânea).

Mariano, G. S., Miranda, J. L. A. \& Metzner, A. C. (2017). Fatores que levam ao desinteresse dos alunos do ensino médio em participar das aulas de educação física. Revista Educação Física UNIFAFIBE, Bebedouro/SP. V, 7 18, setembro. Disponível em: < http://unifafibe.com.br/revistasonline/arquivos/revistaeducacaofisica/sumario/56 /26082017124209.pdf> >. Acesso em: 09 de julho de 2017.

MEC. (2015). Instituto Nacional de Estudos e Pesquisas Educacionais (INEP). Índice de Desenvolvimento da Educação Básica (IDEB). Disponível em: < http://idebescola.inep.gov.br/ideb/consulta-publica > Acesso em: Acesso em: 17 de maio de 2017.

Neu, A. F. \& Terrazzan, E. A. (2017). As produções acadêmico-científicas sobre atuação de professores de educação física veiculadas em periódicos nacionais. In: XIII EDUCERE Congresso Nacional de Educação, Paraná. Anais do XIII EDUCERE. Curitiba: Editora Champagnat. v. 1. p. 16459-16472.

Mészáros, I. (2008). A educação para além do capital / Isteván Mészarós; [tradução Isa Tavares]. -2. ed. - São Paulo: Boitempo, 125 p. - (Mundo do trabalho).

Nidelcoff, M. T. (1989). Uma escola para o povo. $29^{\circ}$ edição. São Paulo - SP: Editora Brasiliense. 102p. 
Nozaki, H. T. (2015). Política educacionais no movimento das mudanças no mundo do trabalho: o caso do trabalho do professor de educação física. In: SOUZA, Maristela da Silva; RIBAS, João Francisco Magno; Calheiros, Vicente Cabrera. Conhecimento em educação fisica: no movimento das mudanças, no mundo do trabalho. Santa Maria: Ed. da UFSM. 188p.

PLHIS. (2013). PLHIS Pelotas - Resumo do Diagnóstico Habitacional. Plano Local de Habitação de Interesse Social: Reunião de início da Etapa 3 - Estratégias de Ação. 7 de fevereiro. Disponível em: < https://pt.slideshare.net/3c _arq-urb/pel estresumodiagnosticov529abr2013> Acesso em: 09 de setembro de 2017.

PNUD - Programa das Nações Unidas para o Desenvolvimento. (2017). Relatório do PNUD destaca grupos sociais que não se beneficiam do desenvolvimento bumano. Disponível em: < http://www.br.undp.org/content/brazil/pt/home/presscenter/articles/2017/03/21/reatrio-do-pnud-destaca-gru pos-sociais-que-n-o-se-beneficiam-do-desenvolvimento-bumano.html >. Acesso em: 17 de maio de 2017.

PNUD. (2016). Informe sobre Desarrollo Humano 2016: Desarrollo Humano para todas las personas. 286p.

Silveira, L. L. \& Frizzo, G. F. E. (2017). A Contextualização do Trabalho Docente de Educação Física na Rede Municipal de Ensino de Pelotas: uma crítica ao sistema capitalista de ensino. Revista Kinesis, 35 (1), Jan - abr., $11-20$.

\section{Notas}

1 O IDH mede o desenvolvimento básico de um país, através da renda, saúde e educação, e assim como o IDHAD, quanto mais próximo de 1 , maior é a igualdade, assim como quanto mais próximo de 0 , maior é a desigualdade.

2 "O presente trabalho foi realizado com apoio da Coordenação de Aperfeiçoamento de Pessoal de Nivel Superior - Brasil (CAPES) - Código de Financiamento 001"

3 Este trabalho foi aprovado pelo Comitê de Ética da Universidade Federal de Pelotas - UFPel - Escola Superior de EF - ESEF sob o número CAAE: 93882518.2.0000.5313, Número do parecer: 2.887.261.

4 O IDEB foi criado em 2007 como forma de avaliar as instituições públicas de educação, por meio do Censo Escolar e provas de desempenho, para que assim possa traçar metas para melhorar a qualidade da educação. Para mais informações acesse: https://www.gov.br/inep/pt-br/areas-de-atuacao/pesquisas-estatisticas-e-indicadores/ideb

5 Para mais elementos demográficos acesse https://www.ibge.gov.br/cidades-e-estados/rs/pelotas.html

6 Os dados do IBGE, foram coletados antes da Pandemia de COVID - 19 no Brasil, deste modo, a coleta destas informações foi realizada, pelos autores do artigo, em maio de 2019. Deste modo, podem existir diferenças entre os dados do período destacado nas referências com os atuais que podem ter sido potencializados pela pandemia.

7 Devemos ressaltar que alguns dos problemas relatados pelos estudantes referem-se à falta de salas de aula, porém, durante as observações, a escola encontrava-se em obras para sua ampliação. 